\title{
An Exploration into the Implementation of Student Research Training Programs
}

\author{
Mi Fang, Qi Gong, Weibin Zhou, Xiaohui Li \\ Teaching Affairs Office, Anhui University, Hefei, China \\ Email: fm556789@163.com
}

Received December 2014

\begin{abstract}
Talent cultivation is the priority of China's talent strategy, which necessitates the education of interdisciplinary innovative talents that meet social needs. This paper presents the possible participation of Anhui University undergraduates in various research training programs and discusses recent exploration of the implementation of Student Research Training Program. It deals with a program management system that conforms to development of Anhui University and describes its effect by tracking employments of the students involved in the program.
\end{abstract}

\section{Keywords}

Student Research Training Program, Training of Innovative Talents, Scientific Research

\section{Introduction}

According to Outline of National Medium and Long-Term Program for Education Reform and Development (2010-2020), "education for all-round development" must be implemented and emphasis should be placed on developing students' "learning ability, innovative spirit and practical ability". Anhui University launched the Student Research Training Program in 2011 to achieve the following objectives: to further develop university students' innovative spirit and practical ability, to apply teachers' scientific research to talents cultivation, to help students receive more elementary training in scientific research earlier, to provide platforms for excellent talents to shine, and to successfully combine scientific research resources with undergraduate talent cultivation.

Student Research Training Program (hereinafter referred to as SRTP) is a research project financing program designed for undergraduates. This work pays close attention to students' participation in the research, which combines education with research [1], and aims at equipping undergraduates with innovative awareness, spirit and ability. SRTP is carried out as a project, with the application done by the instructor and mutual selection between the instructor and students. With the help of existing project resources, students can browse through reference materials, carry out surveys, perform experiments and data analysis, etc. It enables the students to experience and comprehend the essence of scientific research and promote their research competence and capabilities [2].

\section{Implementation and Management of SRTP}

\subsection{Effective Guidance}

Students' participation in the scientific research is to be enhanced on the basis of their interest. Different from

How to cite this paper: Fang, M., Gong, Q., Zhou, W.B. and Li, X.H. (2015) An Exploration into the Implementation of Student Research Training Programs. Open Journal of Social Sciences, 3, 45-49. http://dx.doi.org/10.4236/jss.2015.36010 
postgraduates, undergraduates have more assignments and their knowledge is to be accumulated; however, they are more willing to innovate, whose potential is largely motivated by their interest. Therefore, in addition to guidance, it is more important to develop their interest in scientific research, which helps them understand the process of research. During the research process, the instructor's patient guidance, encouragement and demonstration are very important. The instructor's guidance enables students to study for the purpose of research, enhances their self-study ability and acquaints them with scientific research earlier. Students can come into contact with the frontier of the discipline and understand the development trend of the discipline to establish reasonable knowledge structure.

Led by research subjects, students can accumulate confidence in the participation of scientific research. Because of undergraduates' limited knowledge, the subjects selected should be different from that required for postgraduates. In order to impose less psychological stress and protect their enthusiasm, the selected subjects should be easier and shorter in span. The purpose of SRTP is to develop students' innovative consciousness and ability to innovate; therefore, the selected subjects shall be research-centered, feasible, innovative and practicable, which make them interesting. The research may be experimental research or survey and the subjects should be chosen from projects led by the instructor on the provincial level or above.

\subsection{Process Management}

Process management shall be standardized, striving for macro control. Anhui University has set up a whole range of management systems for thorough monitoring of the approved projects and hereby realizes the macro management and control, as shown in Figure 1. First, only qualified instructor shall apply, the university will organize experts to choose from the applications, which will be announced openly. Second, students will submit materials proving their abilities to the instructor of the project which they want to participate in. It is a two-way selection. Third, the university will summarize results of the two-way selection and announce the results after approval as a confirmation for implementation. After project initiation, the university will organize experts to carry out mid-term inspection and concluding review. When the project is completed, students involved in the project are required to publish at least one thesis in the core journal or apply for one patent. By standardizing process management, the university does its best to fully mobilize the instructor and students, encourage the instructor to invite outstanding students to participate in his project, stimulate students to take an active part in scientific researches, technological production, inventions as well as the writing of research paper and establish a mechanism that the instructor and students interact with the combination of self-study and guidance. In this way, the students' innovative interest is developed and their innovative enthusiasm is motivated [3].

Exercise strict control over progress and implement micro advancing. Instructor responsibility system is adopted for project research. The instructor will accomplish various jobs according to plan, accept the university's monitoring, mid-term inspection and concluding review of the project, and shall submit work report and concluding report. After a student selects the subject, the instructor will instruct the overall process of the research, including project design, technical scheme, experimental practice and results submission, etc., based on his understanding of the student's basic knowledge. The instructor shall exercise strict control over the progress, ensure that the research can be completed efficiently with high quality within the time specified. The instructor shall encourage students to participate in team discussion, help the student study and think independently, help the student to find problems, raise questions and solve them. The instructor will give full play to student's initiative and develop his innovative spirit.

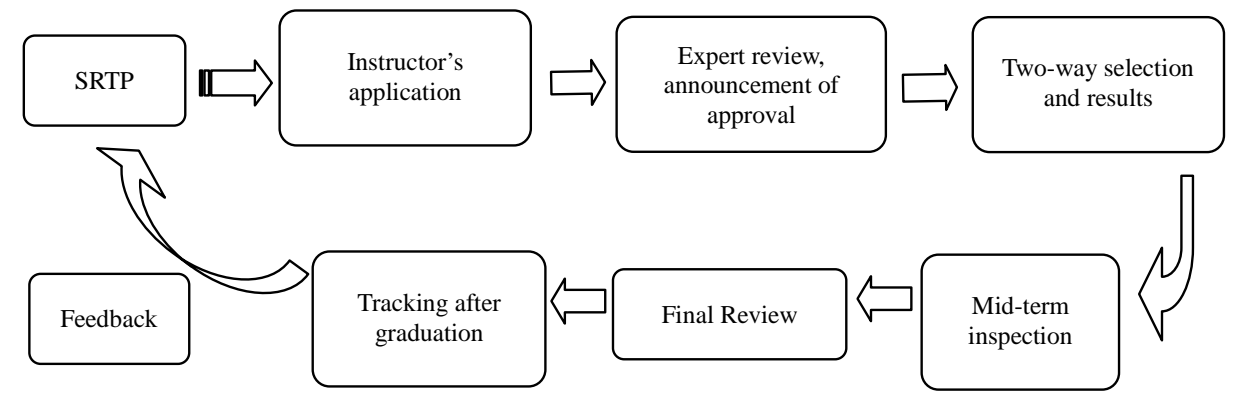

Figure 1. SRTP management flow. 
Improve evaluation system and realize end incentive [4]. After the project is completed, the project team shall fill in Anhui University Concluding Report of SRTP and submit a summary report, with published paper (design), patent, award certificate, etc. The department will carry out primary review of the project and after that the university will organize expert review. The project will be rated as Excellent or Acceptable with certificates. The instructors will be granted 20 credit hours per project and the members of qualified project team will be granted 2 innovative credits.

Track and analyze timely, striving for constant feedbacks. The university carries out tracking and investigation of the students involved in the project after graduation for timely statistics and analysis. By comparing and analyzing how SRTP promotes student employment and enrollment, feedbacks can be provided for the improvement of implementation and management of SRTP.

\subsection{Guarantee of Conditions}

Software. The university has formulated Anhui University SRTP Management Method, which standardizes its organization, application, project management, funds management as well as support and rewards, etc. SRTP is combined with other relevant activities too. The university actively organizes undergraduates to participate in various academic competitions at all levels, hear academic lectures in related fields, join academic activities and discussions in laboratories, and so on. In this way the students can be nurtured by all-round multi-layer scientific researches in an academic atmosphere.

Hardware. The university finances SRTP, with a maximum of 10,000 RMB for social sciences and a maximum of 20,000 RMB for science and engineering. From 2011 to 2014, about 100 SRTPs are approved every year, the funds totaling 7.2 million RMB. In the meantime, the university provides all possible conditions for SRTP and the labs and libraries of all departments are accessible to SRTP students.

\section{Achievements and Effects}

Now we take the first batch of SRTP initiated in 2011 as an example to illustrate the effects of the project. Students involved in the projects are systematically exercised in diversified projects at different levels, which greatly improve their research abilities and achieve fruitful results. According to statistics, the students involved in projects have, as the first author, published 60 academic papers (of which 14 papers in SCI, 1 in EI, 2 in CSCD journals), and have, as co-author, published 24 papers (of which 7 papers in SCI, 4 in EI, 6 in CSCD journals). The students have applied for 7 patents and obtained 1 patent for utility models. The quality of papers published by the students has reached all-time high since the university was founded.

Wang Chunchang, Professor of College of Physics and Material Science, applied for a SRTP entitled Research of Giant Dielectric Property of $\mathrm{A}\left(\mathrm{Fe}_{0.5} \mathrm{Nb}_{0.5}\right) \mathrm{O}_{3}(\mathrm{~A}=\mathrm{Ba}$, Sr) on the basis of his project funded by Chinese Nature Science Foundation and selected students Xu Kebiao of Grade 2008 and Chen Chen of Grade 2009. This project uses Fe-base composite metaperovskite compound as the research material and discusses the application prospect of the material by determining the preparation method of samples and the measuring method of sample's dielectric property. At the beginning of the experiment, owing to the lack of knowledge and experience, the experiment progress was very often hampered which made the two students feel that the knowledge in books is insufficient. The skills in experiment are derived from repeated efforts and questioning. When there are no available rules, students have to explore on their own. For example, how long a high temperature test flow will sustain? How much glue should be mixed for sheet formatting? And how damage to the electrode can be minimized during grinding? With Prof. Wang's patient instructions and strict requirements, they finally nailed down the experiment method, which is also the innovation of the project: to use solid reaction process to prepare high purity experimental samples and to use the entirely new testing software, independently developed by Prof. Wang and others, to test the dielectric property of the samples. After they got experimental data which were a mass of scientific data to them, they are totally confused. However, with Prof. Wang's instructions, they acquired the ability of drawing and data analysis and accomplished their task. Through the exercise, the two students mastered the basic professional knowledge and experimental skill as well as the abilities to analyze, summarize and sort out the experimental data as well as ability to write paper. They reached the conclusion that the material had good dielectric property in low temperature environment so it would have a bright prospect in application, and they have accomplished their tasks very well. The two students published their papers, both as 
first author, entitled "Polaronic relaxation in $\mathrm{LaFeO}_{3}$ " and "Polaronic relaxation in $\mathrm{La}_{0.8} \mathrm{Bi}_{0.2} \mathrm{Fe}_{0.7} \mathrm{Mn}_{0.3} \mathrm{O}_{3}$ " in Materials Letters and Materials Chemistry and Physics, which were collected by SCI. Now the two students are both studying for a master in USTC.

According to statistics, as shown in Figure 2, among 146 students participating in SRTP in 2011, 85 students are admitted to foreign universities, Chinese Academy of Sciences or universities of 211 Project for master degree, which accounted for 58\% of total students involved in SRTP. 55 students are admitted for master degree to universities of 985 Project including Zhejiang University and People's University of China, which accounted for $38 \%$ of total students involved in SRTP. 61 students are employed in scientific research institutions and enterprises.

Most students participating in the SRTP wrote in the summarizing report: after receiving scientific research drills in relevant projects, I not only improved my ability of discovering problems and solving practical problems, but developed my innovative ability of combining theory with practice. Moreover, while conducting research, I obtained an interest of research-oriented study. All these students were highly rated by their tutors in master enrollment and employers in interviews, because of their participation in SRTP and the results they achieved. Wan Jingjing, a student majoring in environmental science enrolled in 2010, who participated in the project of "Research on biological denitrification effect and mechanism of ZVI intensified wastewater with high ammonia-nitrogen" said, "after one year of research drill, with the instruction of our instructor, we got to know how to consult information by using key words, write experiment scheme, adjust experimental design and prepare for experiment. Though there were many unexpected problems in the process, research drills benefited us a lot. We learned the experimental skills and more importantly we learned knowledge in addition to those on the books. We greatly improved our ability to conduct experiment independently.” Wan Jingjing is now studying for a master degree in Department of Environmental Science and Engineering of Fudan University.

Instructors also benefited a lot from their interaction with students in research drills. Prof. Tao Liang, an instructor of School of Computer Science and Technology, said, "While we were instructing the student and achieved the expected results, we were inspired a lot in the process of project implementation. First of all, the undergraduates are the most innovative group who needs instructor's positive guidance. Second, to teach is to learn. Only in communication and interaction can we accurately find problems and instruct timely and solve them. Finally the win-win goal of increasing students' ability of combining theory with practice and improving instructors' instruction has been reached. Real Gabor Transform-based Whispered Voice Understandability Intensifying Project, instructed by Prof. Tao Liang, was completed with excellent results. One student participating in the project was admitted to USTC for master degree and another student was employed by a sci-tech company.

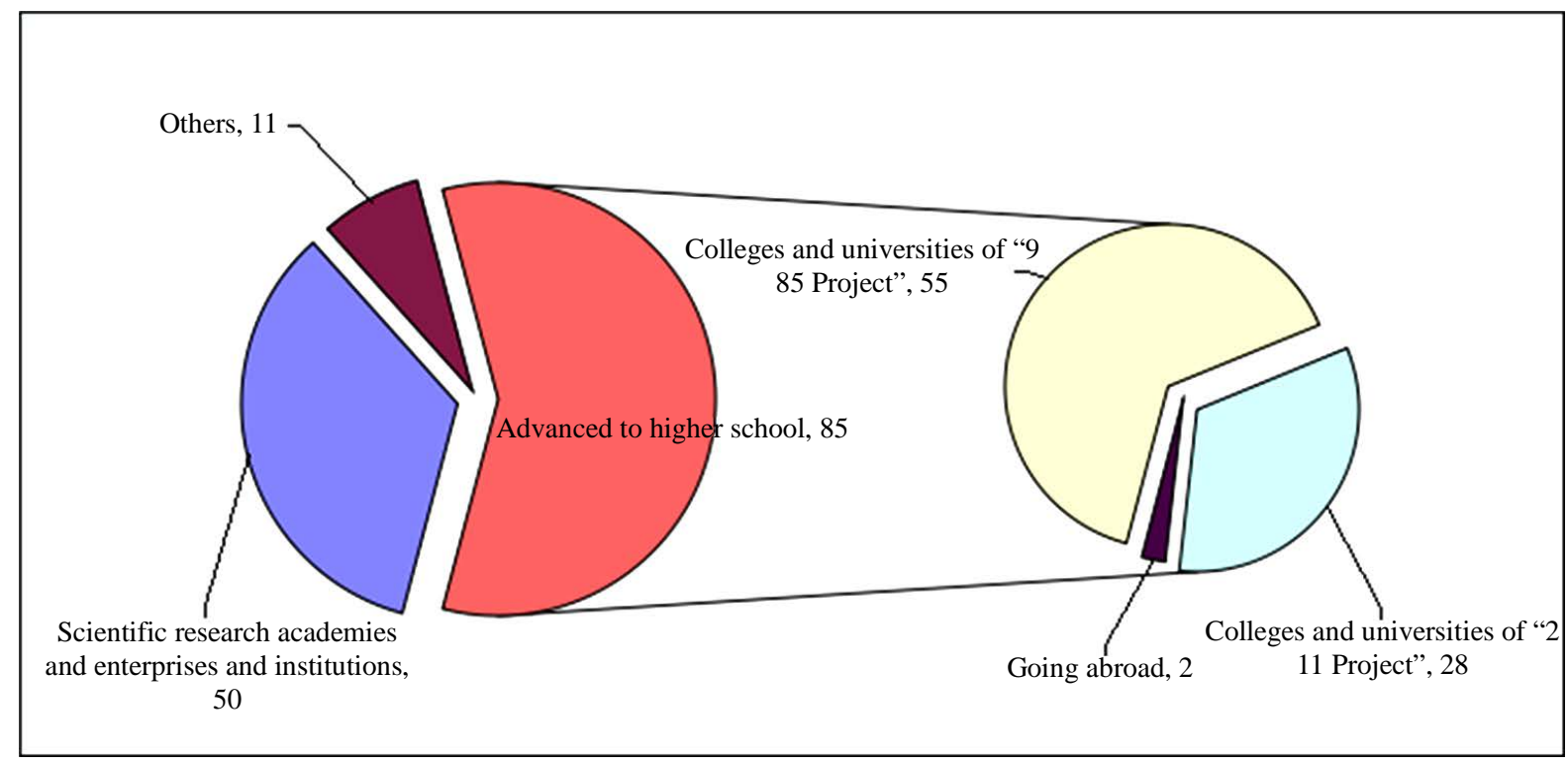

Figure 2. Graduate employment of SRTP students in 2011. 


\section{Conclusion}

Innovation is rooted in practice and developed in practice. To cultivate innovative talents, practice is the foundation. SRTP is an effective way to increase students' innovative ability, practicing ability, teamwork spirit and social competitive edge. Moreover, SRTP plays an important role in developing students' theoretical knowledge, overall practical ability and way of thinking required for scientific research. Through SRTP, Anhui University develops students' innovative thinking, inspires their innovative potential, further improves their practical ability and innovative spirit and enhances the quality of innovative talents.

\section{References}

[1] Ma, J., Sun, R.F. and Peng, F.Y. (2008) Combine Study, Teaching and Research, Develop Innovative PersonnelRetrospect and Prospects of 12-Year SRTP of Tsinghua University. China Education Innovation Herald, 14, 64-66.

[2] Li, Y.F. and Zhu, X.D. (2011) Research Training Program and Development of Students Innovation Ability. China University Teaching, 4, 24-25.

[3] Dong, D.Y. and Shi, B.S.H. (2012) Analysis of Factors Affecting Execution Effect of SRTP. China Higher Education, 29, 65-73.

[4] Li, J.L., Hou, Y., Song, F., Zhang, T.B. and Ji, D.F. (2014) Analysis of Incentive Strategies in Execution of SRTP. China University Teaching, 4, 77-80. 